Check for updates

Cite this: Chem. Sci., 2019, 10, 6876

๑ All publication charges for this article have been paid for by the Royal Society of Chemistry

\title{
Deciphering and quantifying linear light upconversion in molecular erbium complexes $\uparrow$
}

\author{
Bahman Golesorkhi, Alexandre Fürstenberg, (D) Homayoun Nozary \\ and Claude Piguet $\mathbb{D}$ *
}

Single-center light upconversion corresponds to the piling up of low-energy photons via successive linear absorptions: a phenomenon commonly observed in lanthanide-doped low-phonon ionic solids or nanoparticles. Its ultimate miniaturization in molecular complexes opens challenging perspectives in terms of improved reproducibility, chemical control and optical programming. However, high-energy vibrations inherent in coordination complexes severely limit the efficiency of successive excited-state absorptions (ESAs) responsible for the gain in photon energy. By carefully wrapping three polyaromatic ligand strands around trivalent erbium, we managed to induce low-power room temperature nearinfrared ( $\lambda_{\mathrm{exc}}=801 \mathrm{~nm}$ or $\left.966 \mathrm{~nm}\right)$ to visible green $\left(\lambda_{\mathrm{em}}=522 \mathrm{~nm}\right.$ and $545 \mathrm{~nm}$ ) light upconversion within mononuclear coordination complexes $\left[\mathrm{Er}(\mathrm{Lk})_{3}\right]^{3+}$ operating either in the solid state or in nondeuterated solution. The calculated upconversion quantum yields set the zero-level of an elemental erbium-centered molecular ESA mechanism, a value which favorably compares with cooperative upconversion (CU) previously implemented in sophisticated multisite $\mathrm{Yb}_{2} \mathrm{~Tb}$ supramolecular assemblies. The various dependences of the upconverted emission on the incident excitation power imply different mechanisms, which can be tuned by molecular design.

Received 26th April 2019
Accepted 4th June 2019
DOI: $10.1039 /$ c9sc02068c
rsc.li/chemical-science series of intermediate excited states with small radiative rate constants $\left(k_{\mathrm{r}}\right)$, as found for trivalent lanthanides, $\mathrm{Ln}^{3+}$, could be used as relays for successive linear excitations. When such ions are dispersed into low-phonon solids, the non-radiative relaxation pathways $\left(k_{\mathrm{nr}}\right)$ are also minimized to such an extent that linear excitation $\left(k_{\text {exc }}\right)$ becomes competitive with relaxation $\left(k_{\text {relax }}=k_{\mathrm{r}}+k_{\mathrm{nr}}\right)$ and intermediate excited states can efficiently absorb additional photons to reach higher-energy excited levels. The latter sequential piling up of several photons on a single activator (Excited-State Absorption = ESA) exploits linear optics and results in the conversion of low energy infrared photons into visible photons, a phenomenon referred to as upconversion (Scheme 1). ${ }^{9}$ The use of more efficient linear optics combined with the sequential, rather than simultaneous (in NLO), nature of the excitation negates the need for excessively high incident intensities, and upconversion can be achieved using excitation powers that are 5-10 orders of magnitude lower than those required for NLO. A further gain in efficiency of up to two orders of magnitude ${ }^{9 a}$ can be generated by the use of optimized peripheral sensitizers for absorbing photons prior to the stepwise transfer of the accumulated energy onto the activator (energy transfer upconversion = ETU). Under these conditions, upconversion quantum yields as large as $4-12 \%$ have been implemented in multi-centered mixed lanthanide-doped oxides or fluorides. ${ }^{10}$ These encouraging achievements make a multitude of challenging applications possible which intend on (i) reducing the spectral mismatch for solar cell technology, ${ }^{9}$ (ii)
Department of Inorganic and Analytical Chemistry, University of Geneva, 30 Quai E. Ansermet, CH-1211 Geneva 4, Switzerland. E-mail: Claude.Piguet@unige.ch

$\dagger$ Electronic supplementary information (ESI) available. See DOI: $10.1039 / \mathrm{c} 9 \mathrm{sc} 02068 \mathrm{c}$ 
a)

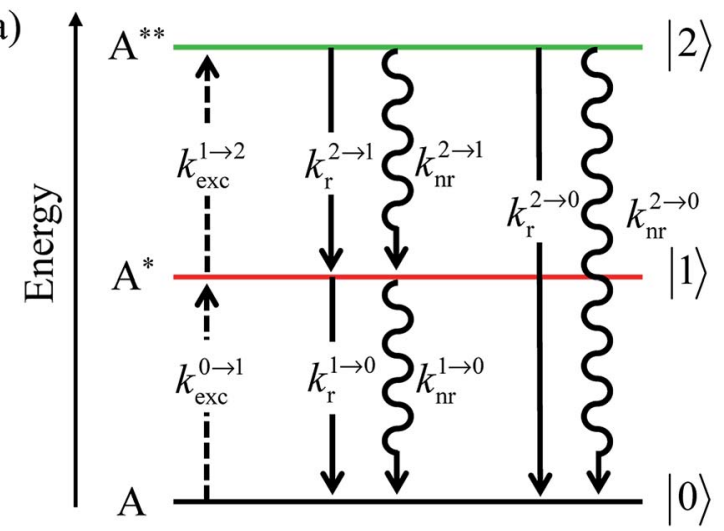

b)

$\left(\begin{array}{c}d N_{\mathrm{A}}^{|0\rangle} / d t \\ d N_{\mathrm{A}}^{|1\rangle} / d t \\ d N_{\mathrm{A}}^{|2\rangle} / d t\end{array}\right)=\left(\begin{array}{ccc}-k_{\text {exc }}^{0 \rightarrow 1} & k_{\text {relax }}^{1 \rightarrow 0} & k_{\text {relax }}^{2 \rightarrow 0} \\ k_{\text {exc }}^{0 \rightarrow 1} & -\left(\begin{array}{c}k_{\text {exc }}^{1 \rightarrow 2} \\ +k_{\text {relax }}^{1 \rightarrow 0}\end{array}\right) & k_{\text {relax }}^{2 \rightarrow 1} \\ 0 & k_{\text {exc }}^{1 \rightarrow 2} & -\left(\begin{array}{c}k_{\text {relax }}^{2 \rightarrow 0} \\ +k_{\text {relax }}^{2 \rightarrow 1}\end{array}\right)\end{array}\right) \times\left(\begin{array}{c}N_{\mathrm{A}}^{|0\rangle} \\ N_{\mathrm{A}}^{|1\rangle} \\ N_{\mathrm{A}}^{|2\rangle}\end{array}\right)$

Scheme 1 (a) Kinetic scheme for the modeling of the linear single-ion ESA process occurring upon off-resonance irradiation into the activator-centered absorption band and (b) associated first-order kinetic equations. $k_{\mathrm{exc}}^{i \rightarrow j}, k_{\mathrm{r}}^{i \rightarrow j}$, and $k_{\mathrm{nr}}^{i \rightarrow j}$ are the first-order rate constants for excitation, radiative decay and non-radiative decay, respectively, and $k_{\text {relax }}^{i \rightarrow j}=k_{r}^{i \rightarrow j}+k_{n r}^{i \rightarrow j}$.

designing near-infrared addressable luminescent bioprobes where the biological tissues are transparent ${ }^{11}$ and (iii) optimizing wave guides, ${ }^{12}$ security inks, ${ }^{13}$ lasers and display devices ${ }^{14}$ and this despite the weak absorption cross sections of $\mathrm{f}-\mathrm{f}$ transitions in lanthanides (in the order of $\left.\sigma \approx 10^{-20} \mathrm{~cm}^{2}\right)^{15}$ or of $\mathrm{d}-\mathrm{d}$ transitions in transition metals (in the order of $\sigma \approx$ $\left.10^{-19} \mathrm{~cm}^{2}\right) \cdot{ }^{16}$

Attempts to reduce the size of upconverting solids toward the nanometric scale for being compatible with high-technology hybrid materials and with their incorporation into biological organisms drastically suffer from surface quenching and difficult reproducibilities. ${ }^{11,17}$ Maximum upconversion quantum yields within the $0.1-0.5 \%$ range have been obtained for optimized nanoparticles after surface passivation ${ }^{18}$ and/or coupling to a surface plasmon for increasing both absorption cross sections and radiative decays. ${ }^{19}$ Because the intensity of the upconverted light $I_{\text {upconversion }}=k_{\mathrm{r}}^{2 \rightarrow 0} N^{|2\rangle}$ reflects the population density of the second excited state $N^{|2\rangle}$, its magnitude drastically depends on the lifetime of the intermediate excited state $\tau^{|1\rangle}=1 /\left(k_{\mathrm{r}}^{1 \rightarrow 0}+k_{\mathrm{nr}}^{1 \rightarrow 0}\right)$. Solving the matrix equation depicted in Scheme $1 \mathrm{~b}$ for trivalent erbium incorporated into long-lived doped solids (for instance $\tau^{|1\rangle}=\mathrm{ms}$ in $\mathrm{Gd}_{2} \mathrm{O}_{2} \mathrm{~S}$ ) under steadystate excitation using reasonable incident pump power (1$10 \mathrm{~W} \mathrm{~cm}^{-2}$ ) predicts mole fractions of $2 \times 10^{-3} \leq N^{|2\rangle} \leq 5 \times 10^{-3}$ for the double excited state $A^{* *}{ }^{20}$ Similar calculations performed for typical short-lived molecular erbium-based complexes possessing high-energy $\mathrm{C}-\mathrm{H}, \mathrm{C}-\mathrm{C}$ and $\mathrm{C}-\mathrm{N}$ oscillators (for instance $\tau^{|1\rangle}=2.8 \mu \mathrm{s}$ in a $\left[\mathrm{GaErL}_{3}\right]$ helix) do not exceed $N^{|2\rangle} \leq 10^{-11} \cdot{ }^{20}$ It is thus not so surprising that singlecentered linear upconversion was originally thought to be undetectable in molecular lanthanide complexes, ${ }^{21}$ and huge incident power intensities around $10^{9} \mathrm{~W} \mathrm{~cm}^{-2}$ produced by modern pulsed femtosecond lasers were required to induce faint upconverted signals for $\left[\operatorname{Ln}(2,6-\text { dipicolinate })_{3}\right]^{3-},[\operatorname{Ln}(\mathrm{EDTA})]^{-}$ $(\mathrm{Ln}=\mathrm{Nd}, \mathrm{Tm}, \mathrm{Er}){ }_{,}{ }^{22}$ and $\left[\mathrm{Tm}(\mathrm{DMSO})_{x}\right]^{3+}$ in solution. ${ }^{23}$ These discouraging results, combined with the approximate $0.1 \mathrm{~W}$ $\mathrm{cm}^{-2}$ power density of terrestrial solar irradiance, ${ }^{9, \boldsymbol{d}}$ paved the way for the exclusive consideration of non-coherent upconversion based on triplet-triplet annihilation (TTA) as the only viable route for performing reliable and workable linear upconversion in molecules. ${ }^{24}$ However, if the latter annihilation process occurs between two discrete triplet-state entities, their formation

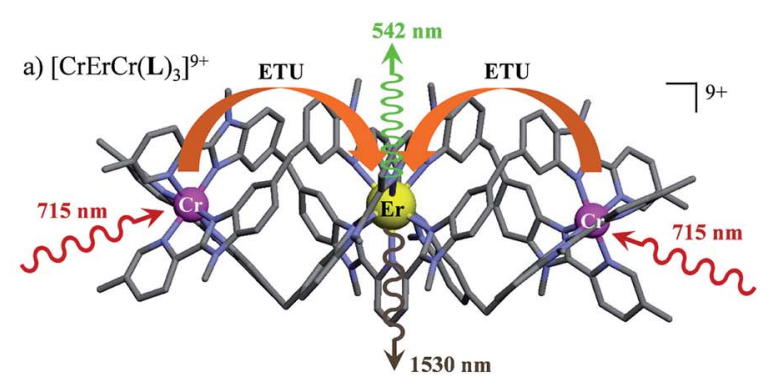

b) $[\operatorname{IR}-806]\left[\operatorname{Er}(\mathbf{L})_{4}\right]$

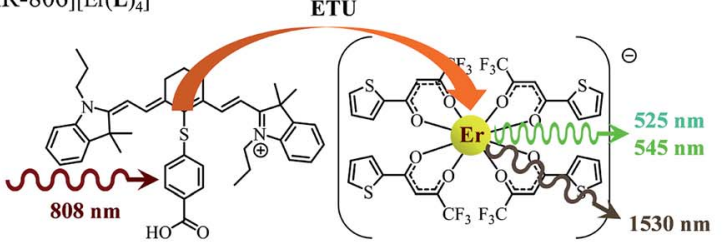

c) $[(\mathbf{L E r}) \mathrm{F}(\mathrm{Er} \mathbf{L})]^{+}$

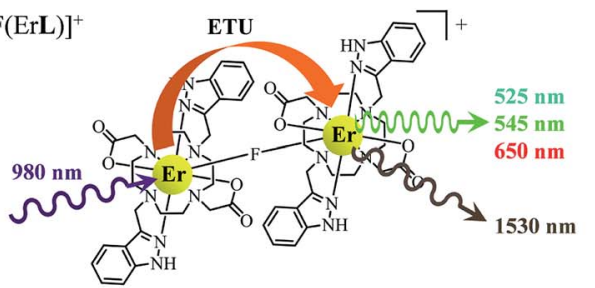

d) $\left[\mathrm{Tb}(\mathrm{YbL})_{2}\right]$

e) $\left[\mathrm{Tb}(\mathrm{YbL})_{2}\right]$
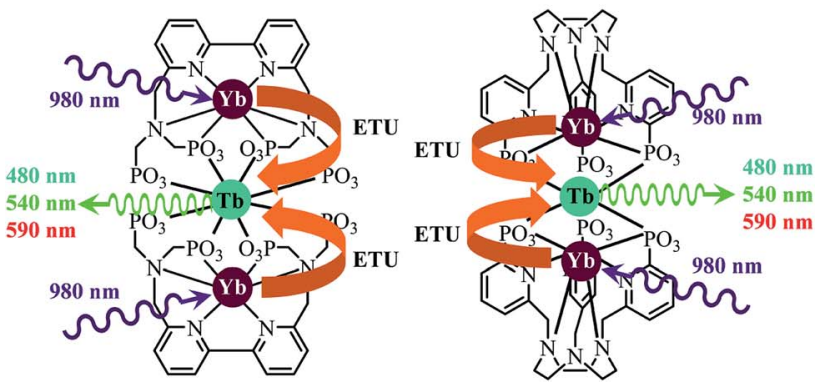

Fig. 1 Erbium-based coordination complexes exhibiting linear upconversion processes following the ETU mechanism. The X-ray crystal structure is shown for (a) $\left[\mathrm{CrErCr}(\mathrm{L})_{3}\right]\left(\mathrm{CF}_{3} \mathrm{SO}_{3}\right)_{9}$ (ref. 28a) and chemical structures deduced from spectroscopic data recorded in solution are depicted for (b) $[\mathrm{IR}-806]\left[\mathrm{Er}(\mathrm{L})_{4}\right]{ }^{29}$ (c) $[(\mathrm{LEr}) \mathrm{F}(\mathrm{LEr})]^{+}$(ref. 30) and $(\mathrm{d})$ and $(\mathrm{e})\left[\mathrm{Tb}(\mathrm{YbL})_{2}\right]{ }^{31}$ 
requires energy diffusion through multiple chromophores and cannot really be considered as a (uni)molecular process. ${ }^{25}$ Let us therefore return to the challenge of implementing singlecentered upconversion in a molecule where (i) the strong coupling with undesirable high-energy oscillators (mainly $\mathrm{O}-\mathrm{H}$ and $\mathrm{C}-\mathrm{H}$ vibrations) limits intermediate excited-state lifetimes and (ii) the small lanthanide absorption cross section $\sigma^{\mathrm{i} \rightarrow \mathrm{j}}$ provides minor excitation rate constants $k_{\text {exc }}^{i \rightarrow j}$ (eqn (1); $\lambda_{\mathrm{P}}$ is the pump wavelength, $P$ is the incident pump intensity, $h$ is the Planck constant and $c$ is the speed of light in a vacuum). ${ }^{26}$

$$
k_{\mathrm{exc}}^{\mathrm{i} \rightarrow \mathrm{j}}=\frac{\lambda_{\mathrm{p}}}{h c} P \sigma^{\mathrm{i} \rightarrow \mathrm{j}}
$$

The decorrelation between light absorption, performed by specific sensitizers, and light-upconversion occurring on an optimized lanthanide activator in multicenter molecular aggregates using the ETU mechanism proved to be less challenging and some protected $\operatorname{Er}(\mathrm{III})$-activators combined with optimized peripheral $\mathrm{Yb}$ (III)-sensitizers in multi-doped metalorganic frameworks or coordination polymers displayed weak upconverted green $\operatorname{Er}\left({ }^{4} \mathrm{~S}_{3 / 2} \rightarrow{ }^{4} \mathrm{I}_{15 / 2}\right)$ and red $\operatorname{Er}\left({ }^{4} \mathrm{~F}_{9 / 2} \rightarrow{ }^{4} \mathrm{I}_{15 / 2}\right)$ signals upon intense $\mathrm{Yb}\left({ }^{2} \mathrm{~F}_{5 / 2} \leftarrow{ }^{2} \mathrm{~F}_{5 / 2}\right)$ excitation. ${ }^{27}$ Encouraged by these preliminary data collected on infinite macroscopic solids, an $\operatorname{Er}(\mathrm{III})$ activator was flanked by a couple of $\mathrm{Cr}(\mathrm{III})$ sensitizers in a molecular triple helix $\left[\mathrm{CrErCrL}_{3}\right]^{9+}$ to give the first molecular-based green upconversion process induced by reasonable power pump intensities (Fig. 1a). ${ }^{28}$ This success was rapidly confirmed for two other molecular sensitizer/activator pairs obtained by host-guest associations in organic solvents $\left([\operatorname{IR}-806]\left[\operatorname{Er}(\mathbf{L})_{4}\right] \text { in Fig. } 1 \mathrm{~b}\right)^{\mathbf{2 9}}$ or in water $\left([(\mathbf{L E r}) \mathrm{F}(\mathbf{L E r})]^{+}\right.$in Fig. 1c). ${ }^{30}$ None of these ETU processes were characterized by quantum yield measurements because of the very faint upconverted signals. In two recent publications, ${ }^{31}$ Charbonnière and co-workers reported on two novel aqueous-phase assemblies made of a central $\mathrm{Tb}$ (III) activator surrounded by two or more $\mathrm{Yb}$ (III) sensitizers $\left(\left[\mathrm{Tb}(\mathrm{YbL})_{2}\right]\right.$ in Fig. 1d and e). Surprisingly, these (supra)molecular entities exhibit detectable near-infrared to green upconversion, for which only cooperative energy transfers may explain the feeding of the high-energy $\operatorname{Tb}\left({ }^{5} \mathrm{D}_{4}\right)$ level (Fig. 1d and e). Though some aspects of the theoretical modeling of the latter cooperative upconversion (CU) mechanism are rather analogous to ETU, its efficiency is usually much weaker because it involves quasi-virtual pair levels between which transitions have to be described by higher-order perturbations. ${ }^{9 a}$ Despite this limitation, Charbonnière and co-workers were able to estimate a quantum yield of $\Phi_{\mathrm{up}}=1.4 \times 10^{-8}$ for the complex depicted in Fig. 2e (deuterated water, room temperature). ${ }^{31 b}$ Boosted by these remarkable results, we reasoned that ultimate miniaturization using a single-site excited-state mechanism (ESA) implemented in a trivalent erbium complex should become an obvious target for setting a zero-level for the quantification of molecular upconversion. Taking advantage of the rare dual visible $\left(\operatorname{Er}\left({ }^{4} \mathrm{~S}_{3 / 2} \rightarrow{ }^{4} \mathrm{I}_{15 / 2}\right)\right.$ at $542 \mathrm{~nm}$, green $)$ and near-infrared $\left(\operatorname{Er}\left({ }^{4} \mathrm{I}_{13 / 2} \rightarrow{ }^{4} \mathrm{I}_{15 / 2}\right)\right.$ at $\left.1520 \mathrm{~nm}\right)$ downshifted emissions observed upon UV excitation of the triple-helical $\left[\operatorname{Er}(\mathbf{L 1})_{3}\right]^{3+}$ complex (Fig. 2a), a chromophore which closely

a)

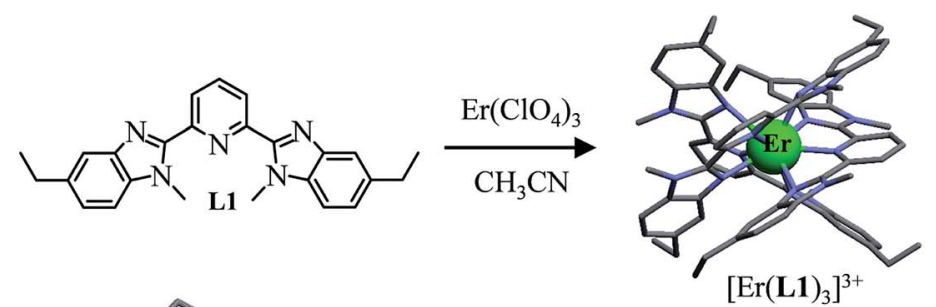

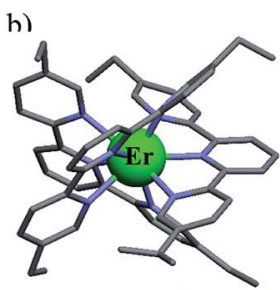

$\left[\operatorname{Er}(\mathbf{L} 2)_{3}\right]^{3+}$

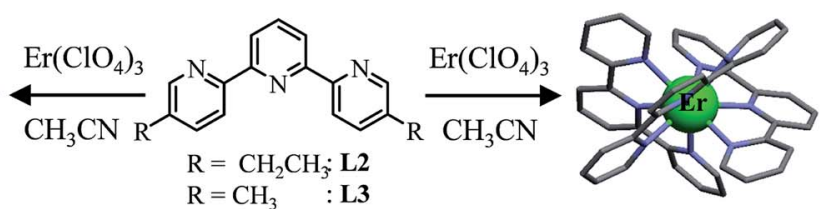

$\left[\operatorname{Er}(\mathbf{L} 4)_{3}\right]^{3+}$

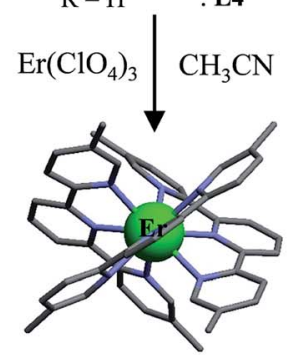

$\left[\operatorname{Er}\left(\mathbf{L} \mathbf{3}_{3}\right]^{3+}\right.$

Fig. 2 Erbium-based coordination complexes exhibiting linear upconversion processes following the ESA mechanism discussed in this work. The X-ray crystal structures are shown for $\left[\mathrm{Er}(\mathrm{L1})_{3}\right]\left(\mathrm{ClO}_{4}\right)_{3} \cdot 1.5 \mathrm{CH}_{3} \mathrm{CN},\left[\mathrm{Er}(\mathrm{L2})_{3}\right]\left(\mathrm{ClO}_{4}\right)_{3},\left[\mathrm{Er}(\mathrm{L3})_{3}\right]\left(\mathrm{ClO}_{4}\right)_{3}$ and $\left[\mathrm{Er}(\mathrm{L} 4)_{3}\right](\mathrm{ClO})_{3} \cdot 1.5 \mathrm{CH}{ }_{3} \mathrm{CN}$. The counter-anions, solvent molecules and $\mathrm{H}$ atoms are omitted for clarity. Color code: grey $=\mathrm{C}$, blue $=\mathrm{N}$, and green $=\mathrm{Er} .{ }^{32}$ 

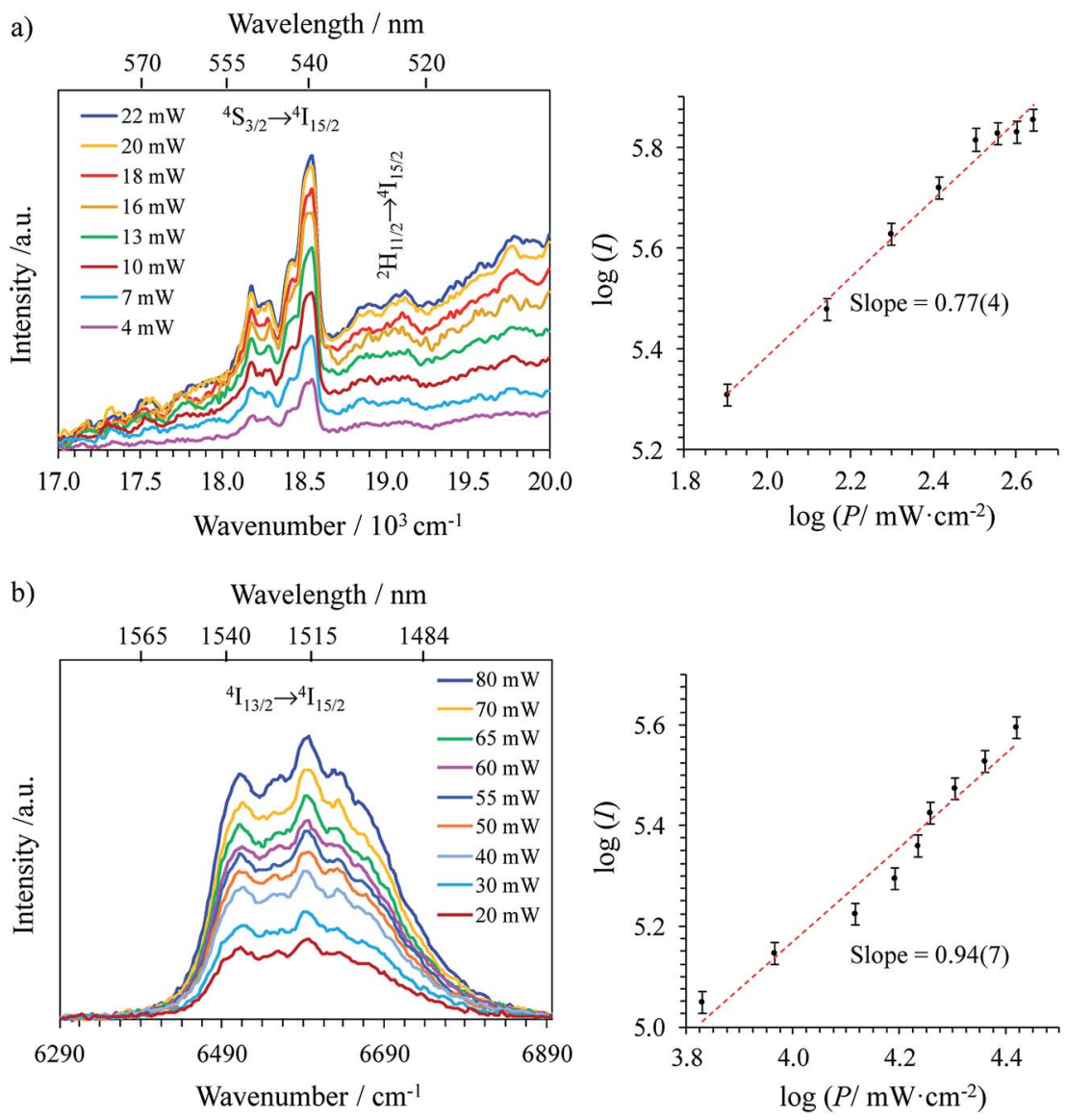

Fig. 3 Downshifted (a) visible and (b) near-infrared emissions and corresponding log-log plots of downshifted intensities / as a function of incident pump intensities $P$ (in $\mathrm{mW} \mathrm{cm}{ }^{-2}$ ) observed for $\left[\mathrm{Er}(\mathrm{L1})_{3}\right]\left(\mathrm{ClO}_{4}\right)_{3}$ (solid state, $298 \mathrm{~K}$ ) upon ligand-centered laser excitation at $401 \mathrm{~nm}$ (24 $938 \mathrm{~cm}^{-1}$ ) and for different incident pump intensities focused on a spot size of $\approx 0.05 \mathrm{~cm}^{2}$.

mirrors the activator unit in the triple helix $\left[\mathrm{CrErCrL}_{3}\right]^{9+}$ (Fig. 1a) ${ }^{32}$ we recently discovered that some weak upconverted green signals could be generated upon direct near-infrared excitation of the erbium center in this system. ${ }^{33}$ Building on these preliminary data, we report here on the quantification and detailed mechanism rationalizing the rare single-site upconversion occurring in $\left[\operatorname{Er}(\mathbf{L} 1)_{3}\right]^{3+}$. Comparison with related optical processes implemented in analogous, but stepwise deprotected $\left[\operatorname{Er}(\mathbf{L} \boldsymbol{k})_{3}\right]^{3+}(\mathbf{L} \boldsymbol{k}=\mathbf{L} 2-\mathbf{L} 4)$, mononuclear triple helices offers an opportunity for establishing some preliminary rules for implementing single-center erbium upconversion in molecular complexes (Fig. 2).

\section{Results and discussion}

Preparation and structural characteristics of the triple-helical complexes

The four tridentate ligands L1-L4 (Fig. 2) have been shown to react with $\operatorname{Er}\left(\mathrm{ClO}_{4}\right)_{3}$ in acetonitrile to give highly stable triple helical complexes $\left[\operatorname{Er}(\mathbf{L} \boldsymbol{k})_{3}\right]^{3+}(<0.1 \%$ dissociated at $10 \mathrm{mM}$ total concentration), which can be crystallized by slow evaporation. ${ }^{32}$ In the crystal structures of $\left[\operatorname{Er}(\mathbf{L k})_{3}\right]\left(\mathrm{ClO}_{4}\right)_{3}$ (Fig. 2), the $\mathrm{Er}$ cations are well-protected from external metallic perturbations (i.e. no cross-relaxation process) since the shortest intermolecular $\mathrm{Er} \cdots \mathrm{Er}$ distances amount to 1.03-1.21 nm. Furthermore, the closest intramolecular $\mathrm{Er} \cdots \mathrm{H}$ contact distance (C-H oscillators) reaches $3.86 \AA$ for $\left[\operatorname{Er}(\mathbf{L 1})_{3}\right]^{3+}(\mathbf{L} 1$ is a 2,6bis(benzimidazol-2-yl)pyridine ligand), but slightly shrinks to 3.42-3.46 $\AA$ for $\left[\operatorname{Er}(\mathbf{L} \boldsymbol{k})_{3}\right]^{3+}(\mathbf{L} \boldsymbol{k}=\mathbf{L} 2-\mathbf{L} 4$, terpyridine-based ligands). Compared with $\mathrm{Er} \cdots \mathrm{H}$ contact distances of $2.85 \AA$ found for the aquo ion $\left[\mathrm{Er}\left(\mathrm{H}_{2} \mathrm{O}\right)_{9}\right]\left(\mathrm{CH}_{3} \mathrm{CH}_{2} \mathrm{SO}_{3}\right)_{3}(\mathrm{O}-\mathrm{H}$ oscillators $),{ }^{34}$ the situation of trivalent erbium in the $\left[\mathrm{Er}(\mathbf{L} \boldsymbol{k})_{3}\right]^{3+}$ complexes is compatible with limited multiphonon relaxation due to coupling with remote high-energy oscillators ${ }^{35}$ as ascertained by the 2-6 $\mu$ s characteristic room-temperature lifetimes reported for the emissive $\operatorname{Er}\left({ }^{4} \mathrm{I}_{13 / 2}\right)$ levels. ${ }^{32}$ While intramolecular $\mathrm{Er} \cdots \mathrm{H}$ distances are not significantly modified in solution for these rigid triple-stranded helicates, ${ }^{36}$ the average intermolecular $\mathrm{Er} \cdots \mathrm{Er}$ distance extends to approximately $6.8 \mathrm{~nm}$ at $10 \mathrm{mM}$ concentration, which makes these metallic centers completely isolated in solution.

\section{Light-downshifting operating in the mononuclear triple- helical complexes}

With these structural characteristics in mind, it is not so surprising that ligand-centered excitation at $401 \mathrm{~nm}$ of these trivalent erbium complexes $\left[\operatorname{Er}(\mathbf{L} \boldsymbol{k})_{3}\right]^{3+}$ in the solid state and in solution systematically showed dual downshifted visible $\operatorname{Er}\left({ }^{4} S_{3 / 2}\right.$ 
$\left.\rightarrow{ }^{4} \mathrm{I}_{15 / 2}\right)$ and near-infrared $\operatorname{Er}\left({ }^{4} \mathrm{I}_{13 / 2} \rightarrow{ }^{4} \mathrm{I}_{15 / 2}\right)$ luminescence at $542 \mathrm{~nm}$ and $1515 \mathrm{~nm}$, respectively (Fig. 3). ${ }^{32}$ The log-log plots of the intensity of the emitted light with respect to the incident power return slopes around 1.0 (Fig. 3), ${ }^{26}$ which are the signatures of single-photon ligand-centered excitation processes followed by energy migration according to the antenna effect (Fig. 4a). ${ }^{32}$ Please note in Fig. 3a the superimposition of the visible $\operatorname{Er}\left({ }^{2} \mathrm{H}_{11 / 2} \rightarrow{ }^{4} \mathrm{I}_{15 / 2}\right)$ and $\operatorname{Er}\left({ }^{4} \mathrm{~S}_{3 / 2} \rightarrow{ }^{4} \mathrm{I}_{15 / 2}\right)$ emission bands with the tails of the residual broad ligand-centered ${ }^{1,3} \pi^{*} \rightarrow{ }^{1} \pi$ bands, which is typical for incomplete metal sensitization via the antenna mechanism.

Alternatively, the low-energy downshifted near-infrared $\operatorname{Er}\left({ }^{4} \mathrm{I}_{13 / 2} \rightarrow{ }^{4} \mathrm{I}_{15 / 2}\right)$ luminescence at $1515 \mathrm{~nm}$ can be sensitized via direct Er-centered excitation at $\lambda_{\text {exc }}=801 \mathrm{~nm}$ of the $\operatorname{Er}\left({ }^{4} \mathrm{I}_{9 / 2}\right.$ $\leftarrow{ }^{4} \mathrm{I}_{15 / 2}$ ) transition (molar absorption coefficients $0.20 \leq \varepsilon_{801} \leq$ $0.24 \mathrm{M}^{-1} \mathrm{~cm}^{-1}$, Table $\left.\mathrm{S} 1 \dagger\right)$ of the $\left[\operatorname{Er}(\mathbf{L} \boldsymbol{k})_{3}\right]^{3+}$ complexes in acetonitrile solution (Fig. 5a) or in the solid state (Fig. S1-S3 in the ESI $\dagger)$. The slopes of $\log (I)-\log (P)$ plots are systematically close to 1.0 (Fig. 5b), a trend in line with single-photon excitations according to the standard mechanism depicted in Fig. $4 \mathrm{~b}$ (left).

Interestingly, the dependence of the emitted downshifted intensity $I_{\mathrm{down}}^{\text {exc:801 }}$ on the temperature $T$ is completely different for the terpyridine derivatives $\left[\operatorname{Er}(\mathbf{L} \boldsymbol{k})_{3}\right]^{3+}(\mathbf{L} \boldsymbol{k}=\mathbf{L 2}-\mathbf{L 4})$ and for the extended 2,6-bis(benzimidazol-2-yl)pyridine analogue $\left[\operatorname{Er}(\mathbf{L 1})_{3}\right]^{3+}$ (Fig. 5c and $\mathrm{S} 4 \dagger$ ). A reasonable explanation considers that the non-radiative $\operatorname{Er}\left({ }^{4} \mathrm{I}_{9 / 2}\right) \Rightarrow \operatorname{Er}\left({ }^{4} \mathrm{I}_{13 / 2}\right)$ relaxation pathway $\left(\Delta E \sim 5900 \mathrm{~cm}^{-1}\right.$, Fig. $4 \mathrm{~b}$ ), required for feeding the emissive $\operatorname{Er}\left({ }^{4} \mathrm{I}_{13 / 2}\right)$ level following $801 \mathrm{~nm}$ excitation, is strongly phononactivated (harmonics and/or combination bands) with terpyridine ligands. This mechanism disappears at low temperature, which overcomes the expected increase in intensity due to the minimizing of the non-radiative quenching of the $\operatorname{Er}\left({ }^{4} \mathrm{I}_{13 / 2} \rightarrow{ }^{4} \mathrm{I}_{15 / 2}\right)$ luminescence at $1515 \mathrm{~nm}$. For the extended 2,6-bis(benzimidazol-2-yl)pyridine binding units in $\left[\operatorname{Er}(\mathbf{L 1})_{3}\right]^{3+}$, the larger density of available vibrations detected in the fingerprint region of the IR spectrum (Fig. S5†) provides some better adapted combinations of vibrational modes for filling the pertinent energy gap $\Delta E=E\left(\operatorname{Er}\left({ }^{4} \mathrm{I}_{9 / 2}\right)\right)-E\left(\operatorname{Er}\left({ }^{4} \mathrm{I}_{13 / 2}\right)\right) \sim 5900 \mathrm{~cm}^{-1}$ and the downshifted luminescence is retained at low temperature (Fig. 5c).

Excitation at $\lambda_{\text {exc }}=966 \mathrm{~nm}$ of the $\operatorname{Er}\left({ }^{4} \mathrm{I}_{11 / 2} \leftarrow{ }^{4} \mathrm{I}_{15 / 2}\right)$ transition (molar absorption coefficients $0.54 \leq \varepsilon_{966} \leq$ $0.66 \mathrm{M}^{-1} \mathrm{~cm}^{-1}$, Table S1†) surprisingly gives $\log (I)-\log (P)$ plots with slopes larger than 2.0 for all complexes (Fig. S6-S8†), which suggests the sequential absorption of at least two photons prior to relaxation into the $\operatorname{Er}\left({ }^{4} \mathrm{I}_{13 / 2}\right)$ level followed by ultimate $\operatorname{Er}\left({ }^{4} \mathrm{I}_{13 / 2} \rightarrow{ }^{4} \mathrm{I}_{15 / 2}\right)$ emission. These unexpected nonlinear dependences, modeled with the mechanism depicted in the right part of Fig. $4 \mathrm{~b}$ (and completed in Fig. $7 \mathrm{~b}$, vide infra), imply that the non-radiative $\operatorname{Er}\left({ }^{4} \mathrm{I}_{11 / 2}\right) \Rightarrow \operatorname{Er}\left({ }^{4} \mathrm{I}_{13 / 2}\right)$ relaxation processes $\left(\Delta E \sim 3700 \mathrm{~cm}^{-1}\right.$, Fig. $\left.4 \mathrm{~b}\right)$ are poorly efficient in all complexes and prevent direct feeding of the emitting $\operatorname{Er}\left({ }^{4} \mathrm{I}_{13 / 2}\right)$ level after excitation at $966 \mathrm{~nm}$.

\section{Lightupconversion operating in the mononuclear triple- helical complexes}

Upon Er-centered excitation at $801 \mathrm{~nm}$ of the $\operatorname{Er}\left({ }^{4} \mathrm{I}_{9 / 2} \leftarrow{ }^{4} \mathrm{I}_{15 / 2}\right)$ transition of the triple helical complexes $\left[\operatorname{Er}(\mathbf{L} \boldsymbol{k})_{3}\right]^{3+}(\mathbf{L} \boldsymbol{k}=\mathbf{L 1 - L 4})$ in the solid state (Fig. 6a, S9 and S10†) and in solution (Fig. 6d),

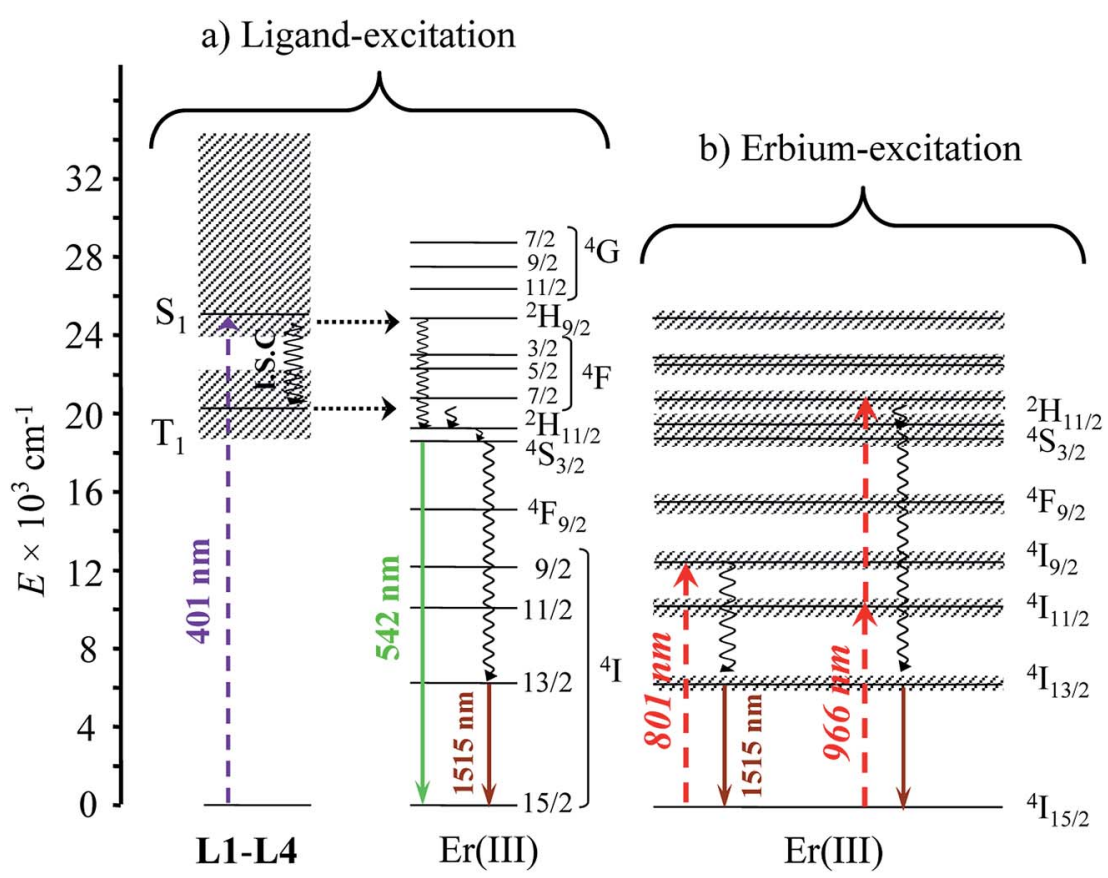

Fig. 4 Jablonski diagram summarizing the downshifting processes following (a) ligand-centered or (b) erbium-centered excitation (dashed upward arrows), energy transfers (dotted horizontal arrows), non-radiative multiphonon relaxation (undulating arrows) and radiative emission processes (straight downward arrows) operating in the complexes $\left[\operatorname{Er}(\mathrm{L} k)_{3}\right]^{3+}(\mathrm{L} k=\mathrm{L} 1-\mathrm{L} 4)$. 

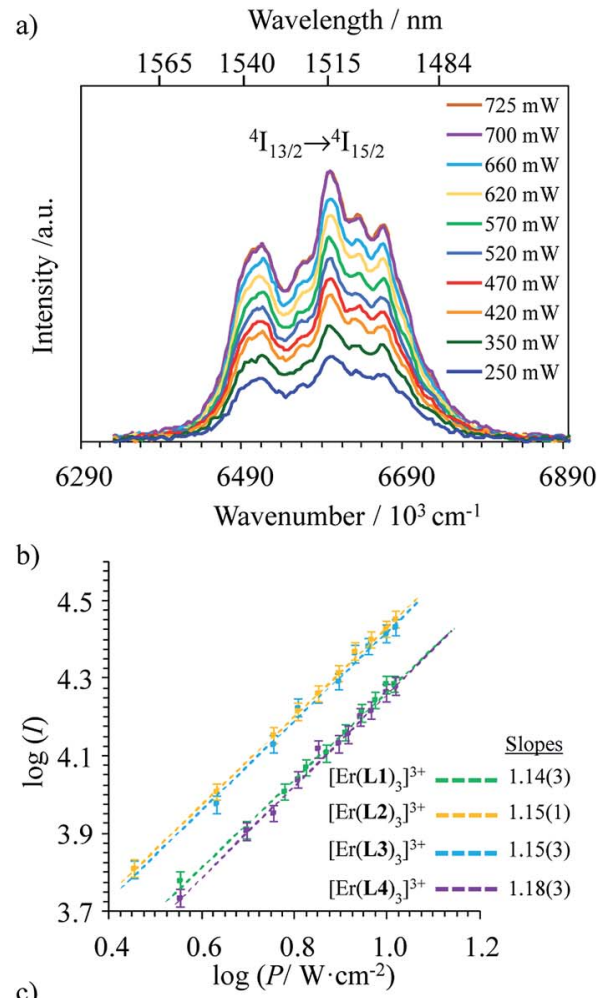

c)

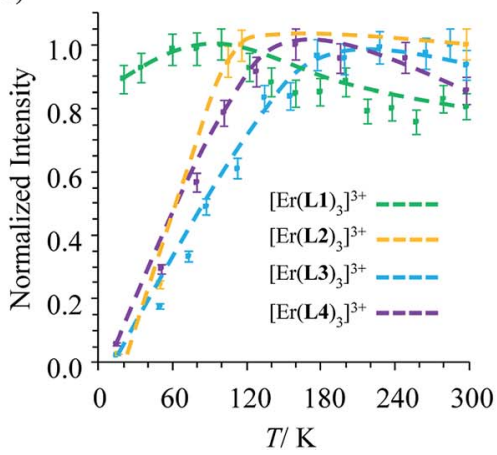

Fig. 5 (a) Near-infrared downshifted $\operatorname{Er}\left({ }^{4} I_{13 / 2} \rightarrow{ }^{4} I_{15 / 2}\right)$ emission observed for $\left[\mathrm{Er}(\mathrm{L1})_{3}\right]\left(\mathrm{ClO}_{4}\right)_{3}$ in acetonitrile $(10 \mathrm{mM}, 298 \mathrm{~K})$ upon laser excitation of the $\operatorname{Er}\left({ }^{4} I_{9 / 2} \leftarrow{ }^{4} I_{15 / 2}\right)$ transition at $\lambda_{\text {exc }}=801 \mathrm{~nm}\left(\tilde{\nu}_{\text {exc }}=\right.$ $12284 \mathrm{~cm}^{-1}$ ) and for different incident pump intensities focused on a spot size of $\approx 0.07 \mathrm{~cm}^{2}$, (b) corresponding log-log plots of downshifted intensities I as a function of incident pump intensities $P$ (in $W$ $\mathrm{cm}^{-2}$ ) for $\left[\operatorname{Er}(\mathrm{Lk})_{3}\right]^{3+}$ in acetonitrile (the straight lines correspond to extrapolated linear fits) and (c) dependences of downshifted intensities $I$ as a function of temperature (solid state, $P=10 \mathrm{~W} \mathrm{~cm}^{-2}$, the dashed lines are only guides for the eye).

the previously discussed downshifted $\operatorname{Er}\left({ }^{4} \mathrm{I}_{13 / 2} \rightarrow{ }^{4} \mathrm{I}_{15 / 2}\right)$ luminescence at $1515 \mathrm{~nm}$ is accompanied by two much weaker, but upconverted, signals at $542 \mathrm{~nm}\left(\operatorname{Er}\left({ }^{4} \mathrm{~S}_{3 / 2} \rightarrow{ }^{4} \mathrm{I}_{15 / 2}\right)\right.$, green $)$ and $522 \mathrm{~nm}\left(\operatorname{Er}\left({ }^{2} \mathrm{H}_{11 / 2} \rightarrow{ }^{4} \mathrm{I}_{15 / 2}\right)\right.$, blue). The limited $1-30 \mathrm{~W} \mathrm{~cm}^{-2}$ excitation power intensities, combined with the lack of residual ligand-centered ${ }^{1,3} \pi^{*} \rightarrow{ }^{1} \pi$ emission bands exclude the contribution of competitive non-linear optical processes involving the ligands. The slopes of $\log (I)-\log (P)$ plots span the 1.5-2.0 range (Fig. 6c) and support the successive linear absorption of two photons by the $\operatorname{Er}(\mathrm{III})$ metallic centers according to the standard ESA mechanism summarized in Fig. $7 a^{26}$

The opposite thermal dependences of the intensities of the upconverted $\operatorname{Er}\left({ }^{4} S_{3 / 2} \rightarrow{ }^{4} I_{15 / 2}\right)$ signals $I_{\text {up }}$ observed for the terpyridine-derivatives $\left[\operatorname{Er}(\mathbf{L} \boldsymbol{k})_{3}\right]^{3+}\left(\mathbf{L} \boldsymbol{k}=\mathbf{L 2}\right.$-L4, $I_{\text {up }}$ increases with $T$, Fig. $6 \mathrm{c}$ and $\mathrm{S} 11 \dagger)$ and $\left[\operatorname{Er}(\mathbf{L 1})_{3}\right]^{3+}\left(I_{\text {up }}\right.$ decreases with $\left.T\right)$ mirror those found for the downshifted near-infrared $\operatorname{Er}\left({ }^{4} \mathrm{I}_{13 / 2}\right.$ $\rightarrow{ }^{4} \mathrm{I}_{15 / 2}$ ) emission (Fig. 5c). This implies that the phononactivated non-radiative $\operatorname{Er}\left({ }^{4} \mathrm{I}_{9 / 2}\right) \Rightarrow \operatorname{Er}\left({ }^{4} \mathrm{I}_{13 / 2}\right)$ relaxation pathway is crucial for both downshifting and upconversion. One can thus safely conclude that the intermediate excited $\operatorname{Er}\left({ }^{4} I_{13 / 2}\right)$ levels act as relays for the ESA mechanism controlling the linear upconversion processes following $801 \mathrm{~nm}$ excitations in these complexes (Fig. 7a). As previously reported for $\operatorname{Er}(\mathrm{III})-$ doped solids, the close proximity of the thermally coupled ${ }^{2} \mathrm{H}_{11 / 2}$ and ${ }^{4} \mathrm{~S}_{3 / 2}$ levels produce dual blue $(522 \mathrm{~nm})$ and green $(542 \mathrm{~nm})$ upconverted emissions, the relative intensity ratios of which may be exploited for thermometry applications (Fig. S11f $\dagger$ ). ${ }^{37}$

Although weak, the latter $\operatorname{Er}\left({ }^{4} \mathrm{~S}_{3 / 2} \rightarrow{ }^{4} \mathrm{I}_{15 / 2}\right)$ and $\operatorname{Er}\left({ }^{2} \mathrm{H}_{11 / 2} \rightarrow\right.$ $\left.{ }^{4} \mathrm{I}_{15 / 2}\right)$ upconverted signals can be unambiguously recorded in solution for $\left[\operatorname{Er}(\mathbf{L} \boldsymbol{k})_{3}\right]^{3+}$ at $10 \mathrm{mM}$ concentration in nondeuterated acetonitrile at room temperature (Fig. 6d). Since all $\left[\operatorname{Er}(\mathbf{L} \boldsymbol{k})_{3}\right]^{3+}$ complexes possess similar absorbance for their $\operatorname{Er}\left({ }^{4} \mathrm{I}_{9 / 2} \leftarrow{ }^{4} \mathrm{I}_{15 / 2}\right)$ transition at $801 \mathrm{~nm}$ (column 2 in Tables 1 and S1, Fig. S12 $\dagger$ ), the stronger emission intensity observed for the 2,6-bis(benzimidazol-2-yl)pyridine derivative $\left[\operatorname{Er}(\mathbf{L 1})_{3}\right]^{3+}$ at a given incident pump intensity can be attributed to an improved quantum yield for the latter complex compared to that for less-protected complexes built with terpyridine derivatives (Fig. 6d). Quantitative data for the upconversion process (up) collected in Table 1 were obtained by using indocyanine green as a reference $\left(\lambda_{\text {exc }}=801 \mathrm{~nm}, \Phi=0.132\right.$ in ethanol at 298 K, Fig. S12 $\dagger)^{38}$ and eqn (2) where $\Phi$ is the quantum yield, $E$ is the integrated emission spectrum, $A$ is the absorbance at the excitation wavelength $\lambda, n$ is the refractive index $\left(n_{\mathrm{CH}_{3} \mathrm{CN}}=1.344\right.$ and $\left.n_{\mathrm{C}_{2} \mathrm{H}_{5} \mathrm{OH}}=1.361\right), P_{\text {exc }}$ is the power intensity of the excitation source at the excitation wavelength and $h \nu_{\text {exc }}$ is the energy of the incident photon at frequency $\nu_{\text {exc }}=\left(c / \lambda_{\text {exc }}\right)$ so that $I_{\text {exc }}=P_{\text {exc }} /$ $h \nu_{\text {exc }}$ is the spectral radiant power measuring the incident excitation intensity. ${ }^{31 b, 39}$ The introduction of a multiplicative factor of 2 takes into account the maximum $50 \%$ efficiency of upconversion. ${ }^{40}$

$$
\frac{\Phi_{\text {up }}}{\Phi_{\text {ref }}}=2 \frac{E_{\text {up }}}{E_{\text {ref }}} \frac{A_{\text {ref }}}{A_{\text {up }}} \frac{n_{\text {ref }}^{2}}{n_{\text {up }}^{2}} \frac{P_{\text {exc,ref }}}{P_{\text {exc,up }}} \frac{h \nu_{\text {exc,up }}}{h \nu_{\text {exc,ref }}}
$$

The magnitude of the upconverted quantum yields $3 \times 10^{-9}$ $<\Phi_{\text {up }}<2 \times 10^{-8}$ calculated for the ESA mechanisms operating in $\left[\operatorname{Er}(\mathbf{L} \boldsymbol{k})_{3}\right]^{3+}$ in acetonitrile is comparable with $\Phi_{\text {up }} \sim 2 \times 1.4 \times$ $10^{-8}=2.8 \times 10^{-8}$ reported for cooperative upconversion achieved by Charbonnière and co-workers in the trinuclear complex $\left[\mathrm{Tb}(\mathrm{YbL})_{2}\right]$ dissolved in deuterated water (Fig. 1e). ${ }^{31 b}$ Despite the advantage of optimizing sensitization in $\left[\mathrm{Tb}(\mathrm{YbL})_{2}\right]$ with the help of peripheral $\mathrm{Yb}(\mathrm{III})$ complexes and the operation of an ETU-type mechanism, the lack of a real intermediate excited state working as a relay on the $\mathrm{Tb}$ (III) activator is a severe 


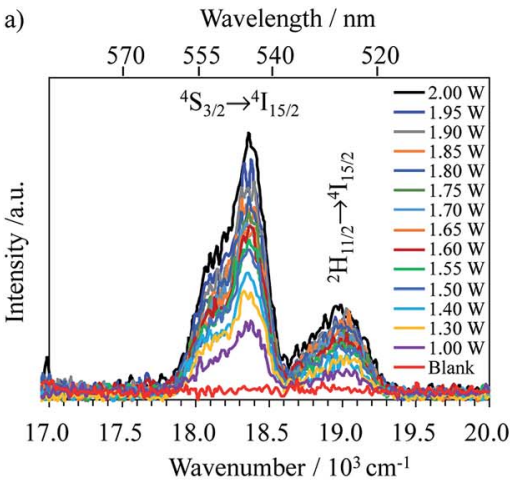

b)

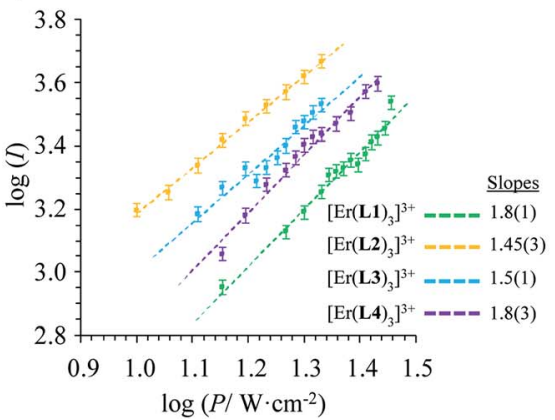

d) Wavelength $/ \mathrm{nm}$

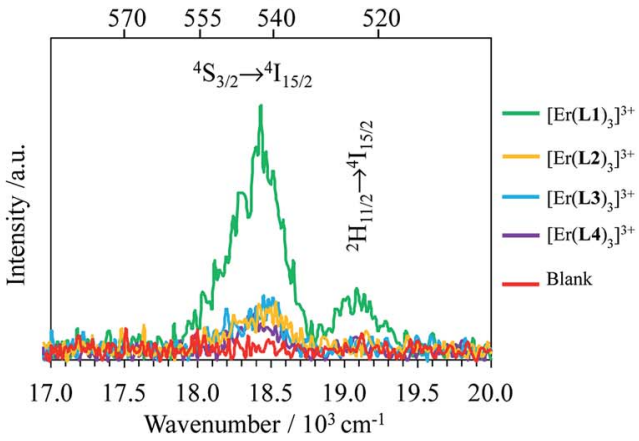

c)

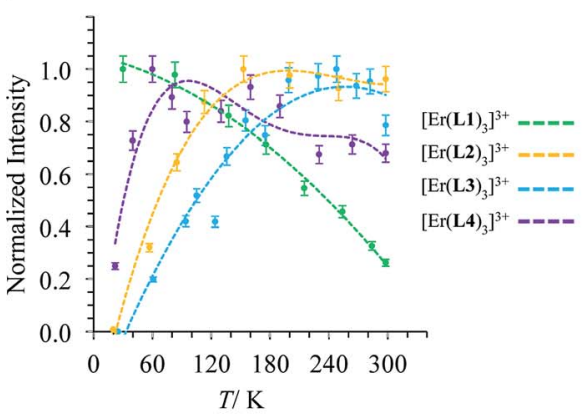

Fig. 6 (a) Upconverted visible $\operatorname{Er}\left({ }^{2} \mathrm{H}_{11 / 2} \rightarrow{ }^{4} \mathrm{I}_{15 / 2}\right)$ and $\operatorname{Er}\left({ }^{4} \mathrm{~S}_{3 / 2} \rightarrow{ }^{4} \mathrm{I}_{15 / 2}\right)$ emissions observed for $\left[\mathrm{Er}(\mathrm{L1})_{3}\right]\left(\mathrm{ClO}_{4}\right)_{3}$ (solid state, $\left.298 \mathrm{~K}\right)$ recorded upon laser excitation of the $\operatorname{Er}\left({ }^{4} I_{9 / 2} \leftarrow{ }^{4} I_{15 / 2}\right)$ transition at $\lambda_{\text {exc }}=801 \mathrm{~nm}\left(\tilde{\nu}_{\text {exc }}=12284 \mathrm{~cm}^{-1}\right)$ and using increasing incident pump intensities focused on a spot size of $\approx 0.07 \mathrm{~cm}^{2}$ (the blank (=red curve) was recorded upon irradiation of the copper plate support covered with silver glue at a maximum intensity $P=29 \mathrm{~W} \mathrm{~cm}^{-2}$ ) and (b) corresponding log-log plots of upconverted intensities / as a function of incident pump intensities $P$ (in $\mathrm{W} \mathrm{cm}^{-2}$ ); the straight lines correspond to extrapolated linear fits. (c) Dependences of upconverted intensities / as a function of temperature (solid state, $P=29 \mathrm{~W} \mathrm{~cm}^{-2}$, the dashed lines are only guides for the eye) and (d) upconverted emissions for $\left[\operatorname{Er}(L k)_{3}\right]^{3+}(L k=L 1-L 4) c o m p l e x e s$ recorded using an incident pump intensity $P=21 \mathrm{~W} \mathrm{~cm}^{-2}$ in acetonitrile solution (c $\sim 10 \mathrm{mM}$ ). The blank (red curve) was recorded from pure acetonitrile solvent using an incident pump intensity $P=21 \mathrm{~W} \mathrm{~cm}^{-2}$.

limitation for final upconversion, a drawback duly mentioned by Auzel in his seminal review when discussing cooperative upconversion. $^{9 \boldsymbol{a}}$ However, the quantum yields collected in Table 1 demonstrate that the extended ligand L1, which moves the high-energy $\mathrm{C}-\mathrm{H}$ oscillators away from the $\operatorname{Er}(\mathrm{III})$ center by circa $10 \%$, simultaneously improves the $\operatorname{Er}\left({ }^{4} \mathrm{I}_{13 / 2}\right)$ intermediate lifetime $(5.57(6) \mu \mathrm{s} \text {, solid state } 298 \mathrm{~K})^{32}$ and upconversion quantum yields in $\left[\operatorname{Er}(\mathbf{L 1})_{3}\right]^{3+}\left(1.6(3) \times 10^{-8}\right)$ compared with terpyridine ligands in $\left[\operatorname{Er}(\mathbf{L} \boldsymbol{k})_{3}\right]^{3+}(\mathbf{L} \boldsymbol{k}=\mathbf{L 2 - L 4} ; 1.88 \mu \mathrm{s} \leq$ $\tau\left(\operatorname{Er}\left({ }^{4} \mathrm{I}_{13 / 2}\right)\right) \leq 2.18 \mu$ s and $3.9(4) \times 10^{-9} \leq \tau\left(\operatorname{Er}\left({ }^{4} \mathrm{I}_{13 / 2}\right)\right) \leq 4.6(5)$ $\left.\times 10^{-9}\right)$.

Related linear upconverted visible signals at $542 \mathrm{~nm}$ $\left(\operatorname{Er}\left({ }^{4} \mathrm{~S}_{3 / 2} \rightarrow{ }^{4} \mathrm{I}_{15 / 2}\right)\right)$ and $522 \mathrm{~nm}\left(\operatorname{Er}\left({ }^{2} \mathrm{H}_{11 / 2} \rightarrow{ }^{4} \mathrm{I}_{15 / 2}\right)\right)$ can be induced in solution (Fig. 8) or in the solid state (Fig. S13 and $\mathrm{S} 14 \dagger)$ via Er-centered excitation of the $\operatorname{Er}\left({ }^{4} \mathrm{I}_{11 / 2} \leftarrow{ }^{4} \mathrm{I}_{15 / 2}\right)$ transition at $966 \mathrm{~nm}$ and using power intensities in the 1$78 \mathrm{~W} \mathrm{~cm}^{-2}$ range. Again, the upconversion process is more efficient in $\left[\operatorname{Er}(\mathbf{L 1})_{3}\right]^{3+}$, when extended 2,6-bis-(benzimadol-2yl)pyridine ligands are wrapped around $\operatorname{Er}(\mathrm{III})$ instead of terpyridines in $\left[\operatorname{Er}(\mathbf{L} \boldsymbol{k})_{3}\right]^{3+}(\mathbf{L} \boldsymbol{k}=\mathbf{L} 2-\mathbf{L 4} ;$ Fig. 8$)$. In the absence of easily accessible organic dyes with well-established quantum yields following excitation at $966 \mathrm{~nm}$, we did not monitor absolute quantum yields at this excitation wavelength. As previously discussed when analyzing downshifting processes (see the mechanism in Fig. 4b), excitation of the $\operatorname{Er}\left({ }^{4} \mathrm{I}_{11 / 2} \leftarrow\right.$ ${ }^{4} \mathrm{I}_{15 / 2}$ ) transition at $966 \mathrm{~nm}$ results in multiple successive linear excitations prior to reaching the intermediate $\operatorname{Er}\left({ }^{4} \mathrm{I}_{13 / 2}\right)$ relay, thus leading to slopes within the 3.0-4.0 range for the linear $\log (I)-\log (P)$ plots characterizing the ultimate upconversion processes (Fig. S13 and S14 $\dagger$ ). The minimum slopes of 2.6-2.7 are still compatible with two- and three-photon processes which avoid the use of the $\operatorname{Er}\left({ }^{4} \mathrm{I}_{13 / 2}\right)$ intermediate excited state as a relay (Fig. $7 \mathrm{~b}$, left). However, the most frequent slopes reach 3.0-4.0 and imply at least one additional successive linear excitation and a 4-phonon mechanism, which is a logical consequence of the involvement of the intermediate $\operatorname{Er}\left({ }^{4} \mathrm{I}_{13 / 2}\right)$ level as a relay (Fig. $7 \mathrm{~b}$ right). The lack of efficient non-radiative $\operatorname{Er}\left({ }^{4} \mathrm{I}_{11 / 2}\right) \Rightarrow \operatorname{Er}\left({ }^{4} \mathrm{I}_{13 / 2}\right)$ relaxation $\left(\Delta E \sim 3700 \mathrm{~cm}^{-1}\right)$, previously responsible for the unusual 2phonon downshifting mechanism observed in these complexes following $966 \mathrm{~nm}$ excitation (Fig. 4b), appears to be a severe handicap for exploiting the 'long-lived' (2-6 $\mu$ s at 298 $\mathrm{K})^{32}$ intermediate $\operatorname{Er}\left({ }^{4} \mathrm{I}_{13 / 2}\right)$ excited level as a relay for promoting visible upconversion (Fig. 7b). Finally, excitations at $966 \mathrm{~nm}$ of the $\operatorname{Er}\left({ }^{4} \mathrm{I}_{11 / 2} \leftarrow{ }^{4} \mathrm{I}_{15 / 2}\right)$ transition exhibit some standard decreases of the upconverted intensities with increasing temperatures (Fig. S15 $\dagger$ ). 

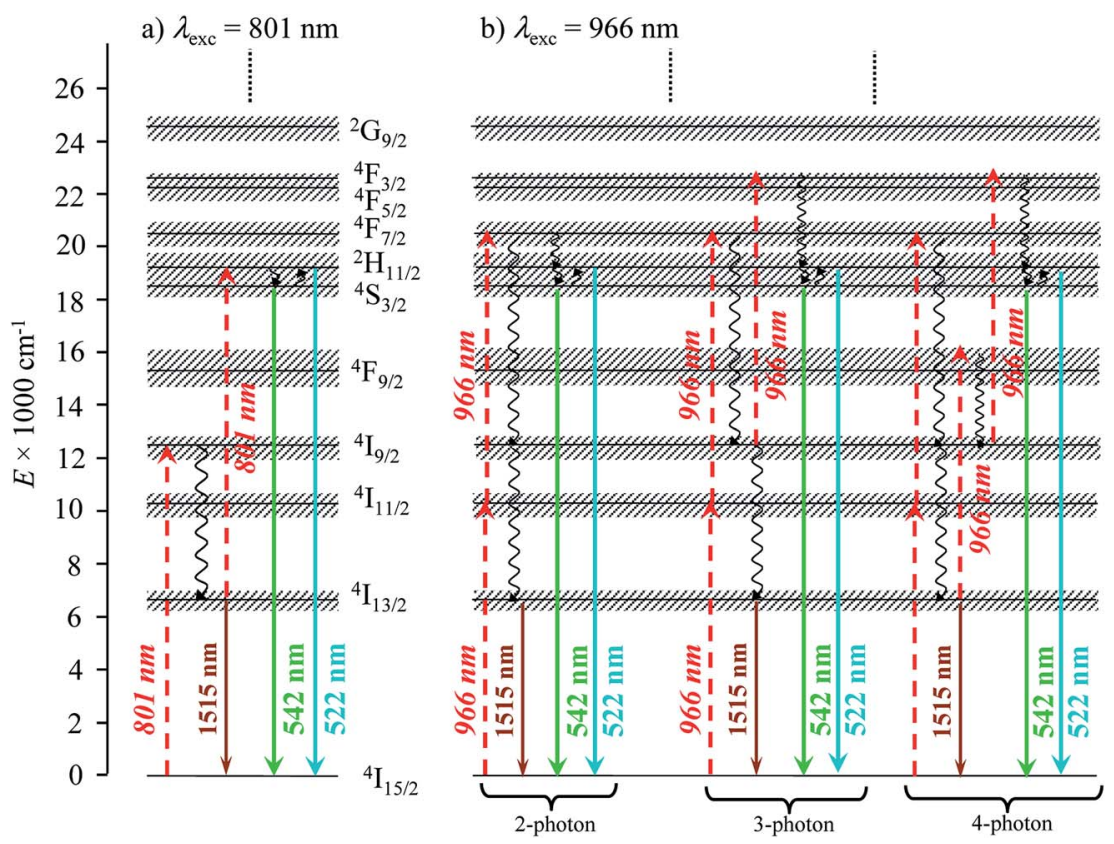

Fig. 7 Jablonski diagram summarizing the mechanisms of the $\mathrm{Er}$-centered upconversion processes operating in the complexes $\left[\mathrm{Er}(\mathrm{Lk})_{3}\right]^{3+}(\mathrm{L} k=$ L1-L4) upon excitation of (a) the $\operatorname{Er}\left({ }^{4} I_{9 / 2} \leftarrow{ }^{4} I_{15 / 2}\right)$ transition at $801 \mathrm{~nm}$ and (b) the $\operatorname{Er}\left({ }^{4} I_{11 / 2} \leftarrow{ }^{4} I_{15 / 2}\right)$ transition at $966 \mathrm{~nm}$. Excitation (dashed upward arrows), non-radiative multiphonon relaxation (downward undulating arrows), thermal equilibria (upward undulating arrows) and radiative emission processes (straight downward arrows).

Table 1 Upconversion luminescence quantum yields $\left(\Phi_{\text {up }}\right)$ calculated for single-centered mononuclear erbium complexes $\left[\operatorname{Er}(\mathrm{L} k)_{3}\right]^{3+}(\mathrm{L} k=$ L1-L4) upon laser excitation of the $\operatorname{Er}\left({ }^{4} I_{9 / 2} \leftarrow{ }^{4} I_{15 / 2}\right)$ transition at $\lambda_{\text {exc }}=$ $801 \mathrm{~nm}\left(\tilde{\nu}_{\text {exc }}=12284 \mathrm{~cm}^{-1}\right)$ and using an incident pump intensity $P=$ $21 \mathrm{~W} \mathrm{~cm}^{-2}$ in acetonitrile solution $(c \sim 10 \mathrm{mM})$ at $298 \mathrm{~K}$

\begin{tabular}{llll}
\hline Compound & $A_{801 \mathrm{~nm}}{ }^{a}$ & $E^{b}$ & $\Phi_{\text {up }}{ }^{c}$ \\
\hline$\left[\operatorname{Er}(\mathbf{L 1})_{3}\right]\left(\mathrm{ClO}_{4}\right)_{3}$ & $7.0 \times 10^{-3}$ & $365(18)$ & $1.6(3) \times 10^{-8}$ \\
{$\left[\operatorname{Er}(\mathbf{L 2})_{3}\right]\left(\mathrm{ClO}_{4}\right)_{3}$} & $5.9 \times 10^{-3}$ & $78(4)$ & $4.1(5) \times 10^{-9}$ \\
{$\left[\operatorname{Er}(\mathbf{L} 3)_{3}\right]\left(\mathrm{ClO}_{4}\right)_{3}$} & $5.3 \times 10^{-3}$ & $78(4)$ & $4.6(5) \times 10^{-9}$ \\
{$\left[\operatorname{Er}(\mathbf{L 4})_{3}\right]\left(\mathrm{ClO}_{4}\right)_{3}$} & $4.4 \times 10^{-3}$ & $55(3)$ & $3.9(4) \times 10^{-9}$
\end{tabular}

${ }^{a}$ Optical density at $801 \mathrm{~nm} .{ }^{b}$ Integrated emission spectrum. ${ }^{c}$ Calculated with respect to indocyanine green (ICG, $\lambda_{\text {exc }}=801 \mathrm{~nm}, \Phi_{\mathrm{r}}$ $=0.132$ in ethanol at $298 \mathrm{~K}) .^{38}$

\section{Conclusions}

Upon ligand-centered or erbium-centered optical excitation, the series of nine-coordinate mononuclear triple-helical erbium(III) complexes $\left[\operatorname{Er}(\mathbf{L} \boldsymbol{k})_{3}\right]^{3+}(\mathbf{L} \boldsymbol{k}=\mathbf{L} \mathbf{1}-\mathbf{L} \mathbf{4})$ all exhibit the expected downshifted near-infrared emission at $1515 \mathrm{~nm}$, which originates from the lowest-energy $\operatorname{Er}\left({ }^{4} \mathrm{I}_{13 / 2}\right)$ excited level (solid state and solution, 10-298 K). While single photon mechanisms characterize sensitization via ligand-centered $\pi^{*}$ $\leftarrow \pi$ light absorption at $401 \mathrm{~nm}$ or erbium-centered $\operatorname{Er}\left({ }^{4} \mathrm{I}_{9 / 2} \leftarrow\right.$ ${ }^{4} \mathrm{I}_{15 / 2}$ ) absorption at $801 \mathrm{~nm}$, the lack of efficient non-radiative $\operatorname{Er}\left({ }^{4} I_{11 / 2}\right) \Rightarrow \operatorname{Er}\left({ }^{4} I_{13 / 2}\right)$ relaxation in these complexes results in unusual two-photon downshifting mechanisms upon $\operatorname{Er}\left({ }^{4} \mathrm{I}_{11 / 2}\right.$ $\leftarrow{ }^{4} \mathrm{I}_{15 / 2}$ ) excitation at $966 \mathrm{~nm}$. Because of vibrational quenching of the near-infrared $\operatorname{Er}\left({ }^{4} \mathrm{I}_{13 / 2} \rightarrow{ }^{4} \mathrm{I}_{15 / 2}\right)$ transition

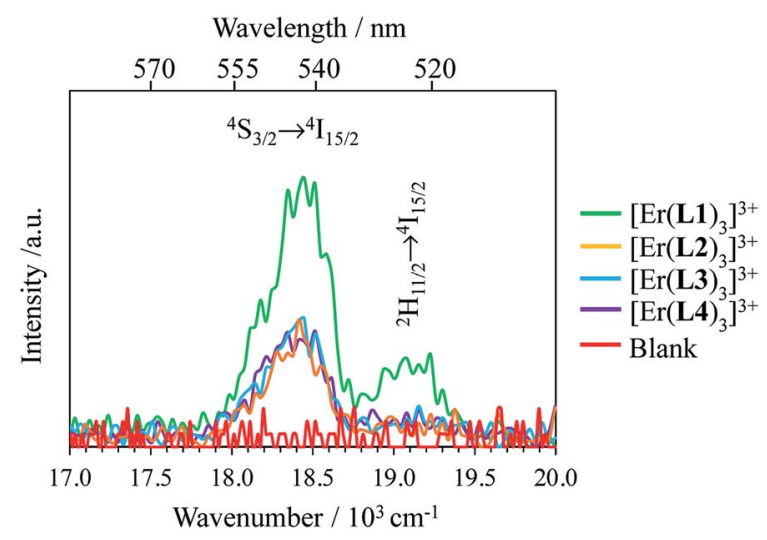

Fig. 8 Upconverted visible $\operatorname{Er}\left({ }^{2} \mathrm{H}_{11 / 2} \rightarrow{ }^{4} I_{15 / 2}\right)$ and $\operatorname{Er}\left({ }^{4} S_{3 / 2} \rightarrow{ }^{4} I_{15 / 2}\right)$ emissions observed for $\left[\mathrm{Er}(\mathrm{L} k)_{3}\right]^{3+}(\mathrm{L} k=\mathrm{L} 1-\mathrm{L} 4)$ complexes recorded upon laser excitation of the $\operatorname{Er}\left({ }^{4} I_{11 / 2} \leftarrow{ }^{4} I_{15 / 2}\right)$ transition at $\lambda_{\text {exc }}=$ $966 \mathrm{~nm}\left(\tilde{\nu}_{\text {exc }}=10350 \mathrm{~cm}^{-1}\right)$ and using an incident pump intensity $P=$ $78 \mathrm{~W} \mathrm{~cm}^{-2}$ in acetonitrile solution ( $c \sim 10 \mathrm{mM}$, Table S1†) at $298 \mathrm{~K}$. The blank (red curve) was recorded from pure acetonitrile solvent using an incident pump intensity $P=78 \mathrm{~W} \mathrm{~cm}^{-2}$.

with high-energy oscillators, the $\operatorname{Er}\left({ }^{4} \mathrm{I}_{13 / 2}\right)$ lifetime is reduced by an approximate factor of three when terminal benzimidazoles in $\left[\operatorname{Er}(\mathbf{L 1})_{3}\right]^{3+}$ (closest intramolecular Er $\cdots \mathrm{H}$ distance $=$ $3.86 \AA)$ are replaced with pyridines in $\left[\operatorname{Er}(\mathbf{L} \boldsymbol{k})_{3}\right]^{3+}(\mathbf{L} \boldsymbol{k}=\mathbf{L} 2-\mathbf{L 4}$; closest intramolecular Er $\cdots \mathrm{H}$ distance $=3.42 \AA$ ). With these photophysical characteristics in mind, the induction of bluegreen visible upconverted signals upon erbium-centered excitation of molecular $\left[\operatorname{Er}(\mathbf{L} \boldsymbol{k})_{3}\right]^{3+}(\mathbf{L} \boldsymbol{k}=\mathbf{L} \mathbf{1}-\mathbf{L} \mathbf{4})$ complexes using reasonable power intensities $\left(1-50 \mathrm{~W} \mathrm{~cm}^{-2}\right)$ is logically 
more efficient in $\left[\operatorname{Er}(\mathbf{L 1})_{3}\right]^{3+}$ and corresponds to a two-photon mechanism for erbium-centered $\operatorname{Er}\left({ }^{4} \mathrm{I}_{9 / 2} \leftarrow{ }^{4} \mathrm{I}_{15 / 2}\right)$ excitation at $801 \mathrm{~nm}$ and to multiple-photon processes (3-4 photons) for $\operatorname{Er}\left({ }^{4} \mathrm{I}_{11 / 2} \leftarrow{ }^{4} \mathrm{I}_{15 / 2}\right)$ excitation at $966 \mathrm{~nm}$. Although weak, the associated quantum yields recorded in acetonitrile $\left(0.4 \times 10^{-8}\right.$ $\leq \Phi_{\text {up }} \leq 1.6 \times 10^{-8}$ for $\lambda_{\text {exc }}=801 \mathrm{~nm}$ ) favorably compare with quantitative data reported for molecular upconversion using multi-center cooperative upconversion in deuterated water. ${ }^{31 b}$ Taking the ESA mechanism operating in these $\left[\operatorname{Er}(\mathbf{L} \boldsymbol{k})_{3}\right]^{3+}$ complexes as the 'zero-level' of efficiency of molecular upconversion, we should remember that Auzel taught us that optimised sensitisation followed by energy transfer according to the ETU mechanism with the help of adapted sensitizers in SA diads $(\mathrm{S}=$ sensitizer, $\mathrm{A}=$ lanthanide activator $)$ may improve the upconversion output by two orders of magnitude. ${ }^{8,9}$ Additionally, moving from molecular SA diads to SAS triads, where $\mathrm{S}$ is a long-lived sensitizer (i.e. millisecond lifetimes as observed in $\mathrm{Cr}(\mathrm{III})$ complexes) may theoretically further improve upconversion by more than three orders of magnitude. ${ }^{20}$ Altogether, the connection of two adapted longlived sensitizers on each side of a central $\operatorname{Er}(\mathrm{III})$ activator to give a structure similar to that shown in Fig. 1a is expected to increase the quantum yield by roughly five orders of magnitude compared to the ESA mechanism, thus reaching $0.1 \%$ efficiency as an upper limit for molecular upconversion using the ETU mechanism. Further optimization exploiting standard perdeuteration ${ }^{41}$ or perfluorination ${ }^{42}$ could be used as wildcards for final tuning. Interestingly, $\operatorname{Er}($ III) protection from high-energy oscillators is helpful, but not sufficient, to design coordination complexes programmed for molecular upconversion. For instance, closely related $1: 2$ complexes $\left[\mathrm{Er}(\mathbf{L} 5)_{2}\left(\mathrm{CF}_{3} \mathrm{SO}_{3}\right)_{2}\right]\left(\mathrm{CF}_{3} \mathrm{SO}_{3}\right) \cdot 2 \mathrm{CH}_{3} \mathrm{CN}$ (L5 is identical to $\mathbf{L 1}$, except for the removal of the peripheral ethyl groups; closest $\mathrm{Er} \cdots \mathrm{H}$ contact distance $=3.70 \AA$, see Fig. $\mathrm{S} 16 \dagger)$ and $\left[\operatorname{Er}(\mathbf{L} 4)_{2}(-\right.$ $\left.\left.\mathrm{CF}_{3} \mathrm{SO}_{3}\right)_{2}\right]\left(\mathrm{CF}_{3} \mathrm{SO}_{3}\right) \cdot 1.5 \mathrm{C}_{2} \mathrm{H}_{5} \mathrm{CN}$ (closest $\mathrm{Er} \cdots \mathrm{H}$ contact distance $=3.40 \AA)$ did not exhibit upconverted signals. ${ }^{32}$ In this context, it is worth remembering here that solid films of $\mathrm{Na}_{3}\left[\operatorname{Er}(2,6 \text { dipicolinate })_{3}\right] \cdot x \mathrm{H}_{2} \mathrm{O}(x=13-15)$, i.e. the most simple triple helical $\operatorname{Er}(\mathrm{III})$ complex with rather long intramolecular Er $\cdots \mathrm{H}$ distances of $5.37 \AA$, also failed in providing either downshifting or upconversion processes in the solid state. ${ }^{21} \mathrm{~A}$ careful look at the crystal structures of the latter complexes ${ }^{43}$ shows that interstitial water molecules accumulate along the threefold axis of the $\left[\operatorname{Ln}(2,6 \text { dipicolinate })_{3}\right]^{3-}$ activators, thus leading to shorter intermolecular $\mathrm{Er} \cdots \mathrm{H}$ distances around $3.56 \AA$, an organization which appears to be incompatible with the detection of any radiative signals following excitation.

\section{Conflicts of interest}

There are no conflicts to declare.

\section{Acknowledgements}

Financial support from the Swiss National Science Foundation is gratefully acknowledged.

\section{References}

1 (a) J. Kerr, Philos. Mag., 1875, 50, 337-348; (b) J. Kerr, J. Phys. Theor. Appl., 1879, 8, 414-418.

2 M. Goeppert-Mayer, Ann. Phys., 1931, 401, 273-294.

3 P. A. Franken, A. E. Hill, C. W. Peters and G. Weinreich, Phys. Rev. Lett., 1961, 7, 118-119.

4 W. Kaiser and C. G. B. Garrett, Phys. Rev. Lett., 1961, 7, 229231.

5 T. H. Maiman, Nature, 1960, 187, 493-494.

6 (a) P. Neveu, I. Aujard, C. Benbrahim, T. Le Saux, J.-F. Allemand, S. Vriz, D. Bensimon and L. Jullien, Angew. Chem., Int. Ed., 2008, 47, 3744-3746; (b) C. Andraud and O. Maury, Eur. J. Inorg. Chem., 2009, 4357-4371; (c) R. Medishetty, J. K. Zareba, D. Mayer, M. Samoc and R. A. Fischer, Chem. Soc. Rev., 2017, 46, 4976-5004; (d) T. N. Nguyen, F. Ebrahim and K. C. Stylianou, Coord. Chem. Rev., 2018, 377, 259-306.

7 N. Bloembergen, Phys. Rev. Lett., 1959, 2, 84-85.

8 (a) F. Auzel, C. R. Acad. Sci., 1966, B262, 1016-1019; (b) F. Auzel, C. R. Acad. Sci., 1966, B263, 819-821.

9 (a) F. Auzel, Chem. Rev., 2004, 104, 139-173; (b) B. M. van der Ende, L. Aarts and A. Meijerink, Phys. Chem. Chem. Phys., 2009, 11, 11081-11095; (c) X. Huang, S. Han, W. Huang and X. Liu, Chem. Soc. Rev., 2013, 42, 173-201; (d) J.-C. G. Bünzli and A.-S. Chauvin, Handbook on the Physics and Chemistry of Rare Earths, ed. J-C. G. Bünzli and V. K. Pecharsky, Elsevier North Holland, Amsterdam, 2014; vol. 44, pp. 169-281; (e) S. Ye, E.-H. Song and Q.-Y. Zhang, Adv. Sci., 2016, 3, 1600302.

10 (a) R. Martin-Rodriguez, S. Fischer, A. Ivaturi, B. Froehlich, K. W. Krämer, J. C. Goldschmidt, B. S. Richards and A. Meijerink, Chem. Mater., 2013, 25, 1912-1921; (b) R. Page, K. Schaffers, P. Waide, J. Tassano, S. Payne, W. Krupke and W. Bischel, J. Opt. Soc. Am. B, 1998, 996-1008. 11 (a) Y. Liu, D. Tu, H. Zhu and X. Chen, Chem. Soc. Rev., 2013, 42, 6924-6958; (b) G. Chem, H. Qiu, P. N. Prasad and X. Chen, Chem. Rev., 2014, 114, 5161-5214; (c) S. Gai, C. Li, P. Yang and J. Lin, Chem. Rev., 2014, 114, 2343-2389; (d) L.-D. Sun, Y.-F. Wang and C.-H. Yan, Acc. Chem. Res., 2014, 47, 1001-1009; (e) D. C. Rodriguez Burbano, R. Naccache and J. A. Capobianco, Handbook on the Physics and Chemistry of Rare Earths, ed. K. A. Gschneidne Jr, J.-C. G. Bünzli and V. K. Pecharsky, Elsevier Science, Amsterdam, 2015, vol. 47, pp. 273-352; (f) X. Zhu, Q. Su, W. Feng and F. Li, Chem. Soc. Rev., 2017, 46, 1025-1039.

12 (a) C. Strohhofer and A. Polman, J. Appl. Phys., 2001, 90, 4314-4320; (b) P. G. Kik and A. Polman, J. Appl. Phys., 2003, 93, 5008-5012.

13 (a) Y. Zhang, L. Zhang, R. Deng, J. Tian, D. Jin and X. Liu, J. Am. Chem. Soc., 2014, 136, 4893-4896; (b) J.-C. G. Bünzli, Eur. J. Inorg. Chem., 2017, 5058-5063.

14 (a) R. M. Macfarlane, J. Lumin., 1990, 45, 346-350; (b) W. Lenth and R. M. Macfarlane, Opt. Photonics News, 1992, 3, 8-15; (c) R. Scheps, Prog. Quantum Electron., 1996, 20, 
271-358; (d) E. Downing, L. Hesselink, J. Ralston and R. M. Macfarlane, Science, 1996, 273, 185-1189.

15 C. Strohhöfer and A. Polman, Opt. Mater., 2003, 21, 705-712.

16 D. R. Gamelin and H. U. Güdel, Acc. Chem. Res., 2000, 33, 235-242.

17 (a) M. Haase and H. Schäfer, Angew. Chem., Int. Ed., 2011, 50, 5808-5829; (b) J. Zhou, Q. Liu, W. Feng, Y. Sun and F. Li, Chem. Rev., 2015, 115, 395-465.

18 J.-C. Boyer and F. C. J. M. van Veggel, Nanoscale, 2010, 2, 1417-1419.

19 (a) S. Han, R. Deng and X. Liu, Angew. Chem., Int. Ed., 2014, 53, 11702-117151; (b) D. M. Wu, A. Garcia-Etxarri, A. Salleo and J. A. Dionne, J. Phys. Chem. Lett., 2014, 5, 4020-4031.

20 Y. Suffren, B. Golesorkhi, D. Zare, L. Guénée, H. Nozary, S. V. Eliseeva, S. Petoud, A. Hauser and C. Piguet, Inorg. Chem., 2016, 55, 9964-9972.

21 C. Reinhard and H. U. Güdel, Inorg. Chem., 2002, 41, 10481055.

22 X. Xiao, J. P. Haushalter and G. W. Faris, Opt. Lett., 2005, 30, 1674-1676.

23 O. A. Blackburn, M. Tropiano, T. J. Sorensen, J. Thom, A. Beeby, L. M. Bushby, D. Parker, L. Natrajan and S. Faulkner, Phys. Chem. Chem. Phys., 2012, 14, 13378-13384.

24 (a) T. N. Singh-Rachford and F. N. Castellano, Coord. Chem. Rev., 2010, 254, 2560-2573; (b) A. Monguzzi, R. Tubino, S. Hoseinkhani, M. Campione and F. Meinardi, Phys. Chem. Chem. Phys., 2012, 14, 4322-4332; (c) T. W. Schmidt and F. N. Castellano, J. Phys. Chem. Lett., 2014, 5, 40624072; (d) V. Gray, K. Moth-Poulsen, B. Albinsson and M. Abrahamsson, Coord. Chem. Rev., 2018, 362, 54-71.

25 L. J. Charbonnière, Dalton Trans., 2018, 47, 8566-8570.

26 (a) M. Pollnau, D. R. Gamelin, S. R. Lüthi and H. U. Güdel, Phys. Rev., 2000, B61, 3337-3346; (b) J. F. Suyver, A. Aebischer, S. Garcia-Revilla, P. Gerner and H. U. Güdel, Phys. Rev. B, 2005, 71, 125123; (c) M. T. Berry and P. S. May, J. Phys. Chem. A, 2015, 119, 9805-9811.

27 (a) D. Weng, X. Zheng, X. Chen, L. Li and L.-P. Jin, Eur. J. Inorg. Chem., 2007, 3410-3415; (b) C.-Y. Sun, X.-J. Zheng, X.-B. Chen and L.-P. Jin, Inorg. Chim. Acta, 2009, 362, 325330M; (c) X. Zhang, B. Li, H. Ma, L. Zhang and H. Zhao, ACS Appl. Mater. Interfaces, 2016, 8, 17389-17394; (d) T. V. Balashova, A. P. Pushkarev, A. N. Yablonskiy, B. A. Andreev, I. D. Grishin, R. V. Rumyantcev, G. K. Fukin and M. N. Bochkarev, J. Lumin., 2017, 192, 208-210; (e) M. Li, S. Gui, D. Tian, E. Zhou, Y. Wang, Y.-F. Han, L. Yin and L. Huang, Dalton Trans., 2018, 47, 12868-12872.
28 (a) L. Aboshyan-Sorgho, C. Besnard, P. Pattison, K. R. Kittilstved, A. Aebischer, J.-C. G. Bünzli, A. Hauser and C. Piguet, Angew. Chem., Int. Ed., 2011, 50, 4108-4112; (b) Y. Suffren, D. Zare, S. V. Eliseeva, L. Guénée, H. Nozary, T. Lathion, L. Aboshyan-Sorgho, S. Petoud, A. Hauser and C. Piguet, J. Phys. Chem. C, 2013, 117, 26957-26963; (c) D. Zare, Y. Suffren, L. Guénée, S. V. Eliseeva, H. Nozary, L. Aboshyan-Sorgho, S. Petoud, A. Hauser and C. Piguet, Dalton Trans., 2015, 44, 2529-2540.

29 I. Hyppänen, S. Lahtinen, R. Äritalo, J. Mäkelä, J. Kankare and T. Soukka, ACS Photonics, 2014, 1, 394-397.

30 A. Nonat, C. F. Chan, C. Platas-Iglesias, Z. Liu, W.-T. Wong, W.-K. Wong, K.-L. Wong and L. J. Charbonnière, Nat. Commun., 2016, 11978.

31 (a) N. Souri, P. Tian, C. Platas-Iglesias, K.-L. Wong, A. Nonat and L. J. Charbonnière, J. Am. Chem. Soc., 2017, 139, 14561459; (b) A. Nonat, S. Bahamyirou, A. Lecointre, F. Przybilla, Y. Mély, C. Platas-Iglesias, F. Camerel, O. Jeannin and L. J. Charbonnière, J. Am. Chem. Soc., 2019, 141, 1568-1576.

32 B. Golesorkhi, L. Guénée, H. Nozary, A. Fürstenberg, Y. Suffren, S. V. Eliseeva, S. Petoud, A. Hauser and C. Piguet, Chem.-Eur. J., 2018, 24, 13158-13169.

33 B. Golesorkhi, H. Nozary, L. Guénée, A. Fürstenberg and C. Piguet, Angew. Chem., Int. Ed., 2018, 57, 15172-15176.

34 J. A. A. Ketelaar, Physica, 1937, 4, 619-630.

35 E. Kreidt, C. Kruck and M. Seitz, Handbook on the Physics and Chemistry of Rare Earths, ed. J-C. G. Bünzli and V. K. Pecharsky, Elsevier Science, Amsterdam, 2018, vol. 53, pp. 35-79.

36 S. Rigault, C. Piguet, G. Bernardinelli and G. Hopfgartner, J. Chem. Soc., Dalton Trans., 2000, 4587-4600.

37 Z. Chouahda, J. P. Jouart, T. Duvaut and M. Diaf, J. Phys.: Condens. Matter, 2009, 21, 245504.

38 K. Rurack and M. Spieles, Anal. Chem., 2011, 83, 1232-1242. 39 J. Verhoeven, Pure Appl. Chem., 1996, 68, 2283-2286.

40 V. Gray, D. Dzebo, M. Abramhamsson, B. Albinsson and K. Moth-Poulsen, Phys. Chem. Chem. Phys., 2014, 16, 10345-10352.

41 C. Doffek and M. Seitz, Angew. Chem., Int. Ed., 2015, 54, 9719-9721.

42 G. Mancino, A. J. Ferguson, A. Beeby, N. J. Long and T. S. Jones, J. Am. Chem. Soc., 2005, 127, 524-525.

43 (a) J. Albertsson, Acta Chem. Scand., 1972, 26, 1023-1044; (b) N. Hojnik, M. Kristl, A. Golobič, Z. Jagličić and M. Drofenik, J. Mol. Struct., 2015, 1079, 54-60; (c) S. M. Elahi and M. V. Rajasekharan, ChemistrySelect, 2016, 1, 6515-6522. 